\title{
Concreteness without imagery in PA learning
}

\section{JOHN C. YUILLE, DEPARTMENT OF PSYCHOLOGY, MCGILL UNIVERSITY, Montreal, Canada}

A group of $S$ s rated nouns on abstractness-concreteness (C), emotionality, $(e)$, and three semantic scales. A second group of $S$ s learned a list of 16 paired associates $(P A)$ constructed from these nouns. Rated $C$ and $e$ were covaried on both the stimulus and response side of pairs. The rated capacity of the nouns to evoke imagery (I) was held constant. While the covaried attributes did affect learning, the pattern of high-low $C$ differences was different than previous studies with I covaried. These results were interpreted as support for noun $I$ being the effective variable underlying the $C$ effect in PA learning.

A recent series of studies (e.g., Paivio, 1965; Paivio, Yuille, \& Smythe, 1966) has shown that noun concreteness (C), especially of the stimulus term, is related positively to paired-associate (PA) learning. This effect has been linked theoretically to the imagery (I) evoking capacity of nouns (cf. Paivio, 1967). Thus, concrete noun stimuli presumably elicit images that can serve as mediators in PA learning. Support for this hypothesis has been obtained from a number of sources, for example, concrete nouns exceed abstract nouns in their rated capacity to evoke I (Paivio, Yuille, \& Madigan, 1968), and Ss report using imagery more often to mediate concrete rather than abstract pairs of nouns (Paivio et al, 1966).

In an attempt to demonstrate that the effect of noun $C$ is due to covarying 1, Paivio et al (1966) conducted two experiments. In one they manipulated stimulus and response $\mathrm{C}$ while controlling rated $I$, and in the second I was varied while $C$ was held constant. Although stimulus I was found to have a positive effect with $\mathrm{C}$ controlled, supporting the hypothesis, noun $\mathrm{C}$ was also found to have an effect independent of I. Paivio et al (1966) suggested that this latter effect may have been due to insensitive measures of $C$.

Since the precise determination of the variables contributing to the effects of noun $\mathrm{C}$ is essential to the imagery hypothesis proposed by Paivio (1965), a further examination of the relationship between $I$ and $C$ in learning appears necessary. Recently, Paivio et al (1968) obtained 7-point scale ratings of $\mathrm{C}$ and $\mathrm{I}$, as well as production meaningfulness data, for 925 nouns. These data permit a test of whether $\mathrm{C}$ has an effect on PA learning with I controlled. Paivio et al (1968) report that although $C$ and I correlate .83 in the total sample, 51 nouns show considerably higher ratings on I than $C$. The use of this "peculiar" subsample of nouns permits independent manipulation of $C$. A secondary purpose of this study was to determine, if possible, how the 51 nouns differ from the rest of the sample. Paivio et al (1968) observed that these nouns tend to have evaluative connotations, and special attention was paid to that dimension of meaning.

\section{METHOD}

Noun ratings. Twenty-seven Ss (10 males, 17 females) rated 40 nouns on each of five bipolar 7-point scales. The nouns were chosen from the 925 nouns used by Paivio et al (1968). Twenty of the nouns (abstract nouns) were selected from the group of 51 "unusual" nouns having medium I but low $\mathrm{C}$ ratings; the other twenty nouns (concrete nouns) had relatively high $\mathbf{C}$ ratings but were comparable to the 20 unusual nouns in their I, meaningfulness, and frequency values.

The five bipolar scales were defined by the following pairs of adjectives: concrete-abstract, good-bad, active-passive, hard-soft, and emotionalunemotional. The "good," "active," and "hard" scales were included as representative of the three meaning dimensions defined by Osgood, Suci, \& Tannenbaum (1957). The "concrete" and "emotional" scales were included in order to assess the relationship between $\mathrm{C}$ and emotionality.

Booklets containing the 40 nouns, four nouns per page, were prepared with the five scales typed below each noun. The first page of each booklet contained mimeographed instructions taken from Osgood et al (1957, pp. 82-84).

The Ss were presented with the booklets during a regular class period and allowed as much time as necessary to finish the rating task.
Table 1

Mean Ratings for Concrete and Abstract Nouns for Each of Five Bipolar Scales

SCALES "concrete" "good" "active" "hard" "emotional"

\begin{tabular}{llllll} 
CONCRETE NOUNS & 6.17 & 4.29 & 4.11 & 4.13 & 3.81 \\
ABSTRACT NOUNS & 2.67 & 4.29 & 5.31 & 3.89 & 5.99 \\
\hline
\end{tabular}

SDs range from .47 to 1.78 .

PA Learning. The 40 nouns used in the rating phase were paired to form five pairs each that were concrete-concrete $(C-C)$, concrete-abstract $(C-A)$, abstract-concrete $(\mathrm{A}-\mathrm{C})$, and abstract-abstract $(\mathrm{A}-\mathrm{A})$. A second PA list was constructed by repairing the nouns so that the words used for $\mathrm{C}-\mathrm{C}$ and $\mathrm{A}-\mathrm{A}$ pairs now formed $\mathrm{C}-\mathrm{A}$ and $\mathrm{A}-\mathrm{C}$ pairs, and vice versa. Two additional lists resulted from "turning over" the pairs in the two original lists.

Standard PA learning instructions (Paivio, 1965) and the four PA lists were recorded on magnetic tape. The Ss, tested in groups of five or six, heard the instructions and then received four alternating learning and recall trials with one of the four lists. The interpair interval during learning was $2 \mathrm{sec}$, the interstimulus interval during recall was $8 \mathrm{sec}$. The Ss wrote their responses on recording sheets.

A total of 36 Ss (15 males, 21 females) learned the PA lists. RESULTS AND DISCUSSION

Noun ratings. The mean ratings for the 20 concrete and 20 abstract nouns for each of the five scales appear in Table 1. The labels given for each scale denote the defining adjective for the rating of 7 . The major differences between the two groups of nouns are on the concrete-abstract scale, which replicates Paivio et al (1968), and on the emotional-unemotional scale. The $C$ rating values correlate +.96 with those obtained by Paivio et al, indicating the generality of the original ratings. The emotional and concrete ratings correlate -.83 , evidence for emotionality being the variable causing separation of scaled $I$ and $C$ values.

PA learning. Learning scores for Ss receiving the four different lists were comparable, and their data were pooled. The mean recall scores for the four types of pairs for each trial appear in Table 2. A repeated measures analysis of variance was performed on the data with trials, stimulus $\mathrm{C}$, and response $\mathrm{C}$ as factors. The trials ( $\mathrm{F}$ $=26.28, \mathrm{df}=3 / 105, \mathrm{p}<.01)$, and stimulus $(\mathrm{F}=39.72, \mathrm{df}=$ $1 / 35, p<.01)$ main effects were significant as well as the interaction of these two factors $(F=2.78$, df $=3 / 105, p<.05)$. The stimulu: by response $C$ interaction $(F=15.66, d f=1 / 35, p<$ $.01)$ and the three-way interaction $(\mathrm{F}=3.84, \mathrm{df}=3 / 105, \mathrm{p}<.05)$ were also significant. A trial by trial examination of the recall scores will clarify these effects.

On the first trial the effects of stimulus and response $\mathrm{C}$ were inconsistent. Recall of $\mathrm{C}-\mathrm{C}$ pairs was higher than for $\mathrm{C}-\mathrm{A}$ or $\mathrm{A}-\mathrm{C}$ pairs $(t=3.32, \mathrm{df}=35, \mathrm{p}<.01)$ but not for $\mathrm{A}-\mathrm{A}$ recall $(\mathrm{t}=1.50)$. These results are unlike any obtained in previous research manipulating $\mathrm{C}$. The second and third trial results were more similar with past findings. Recall of $\mathrm{C}-\mathrm{C}$ pairs was superior to all

Table 2

Mean Recall for Each Type of Pair for Each Trial

\begin{tabular}{lllll} 
& & \multicolumn{3}{c}{ Trials } \\
\cline { 2 - 5 } $\begin{array}{l}\text { Type of } \\
\text { Pair }\end{array}$ & 1 & 2 & 3 & 4 \\
\hline C-C & 2.03 & 3.64 & 4.47 & 4.81 \\
C-A & 1.36 & 3.14 & 4.03 & 4.58 \\
A-C & 1.00 & 2.53 & 3.53 & 4.25 \\
A-A & 1.69 & 2.67 & 3.47 & 4.31 \\
\hline
\end{tabular}

SDs range from 0.52 to 1.53 . 
Table 3

Matrix of Correlations for 40 Nouns

\begin{tabular}{lrrrrrrr} 
& 1 & 2 & 3 & 4 & 5 & 6 & 7 \\
\hline 1. Stimulus recall & .29 & $.43^{* *}$ & .15 & $-35^{*}$ & $-32^{*}$ & $-48^{* *}$ \\
2. Response recall & & & -.03 & 11 & 00 & 22 & 08 \\
3. Concreteness & & & -.10 & .16 & $-.63^{*}$ & $-.83^{*}$ \\
4. Good - bad & & & & $-.55^{*}$ & .11 & -.01 \\
5. Hard - soft & & & & & +.01 & -.11 \\
6. Active - passive & & & & & & $.64^{* *}$ \\
7. Emotional - unemotional & & & & & & \\
${ }^{*} p<.05$ & & & & & & \\
$* * 0.01$ & & & & & & &
\end{tabular}

other types $(t=2.48, \mathrm{df}=35, \mathrm{p}<.01)$, and $\mathrm{C}$-A recall reliably exceeded $A-C$ recall $(t=3.02, d f=35, p<.01)$. On the fourth trial, Ss recalled C-A, A-C and A-A pairs equally well $(\mathrm{t}=1.83)$ while $\mathrm{C}-\mathrm{C}$. recall was higher than $\mathrm{A}-\mathrm{C}$ or $\mathrm{A}-\mathrm{A}$ recall $(\mathrm{t}=2.78, \mathrm{df}=$ $35, \mathrm{p}<.01$ ).

The interaction effects obtained in the overall analysis are accounted for by the strong stimulus effects on Trials 2 and 3 but not on Trials 1 and 4 and response effects only with concrete stimulus pairs on the second and third trials.

Correlations were computed between mean total recall scores for each word as stimulus and response and the ratings for each noun. The correlation matrix appears in Table 3. Stimulus $\mathrm{C}$ but not response $\mathrm{C}$ is significantly correlated with recall. However, the -.48 correlation between stimulus emotionality and recall indicates that unemotional words were recalled better than emotional
Partial correlations computed between stimulus recall and $\mathrm{C}$ with emotionality partialled out indicates that $C$ was not related to recall $(r=.06)$. Also, emotionality and stimulus recall correlate only -.24 with the $\mathrm{C}$ effect partialled. Three types of evidence suggest that variation of noun $C$ has little or no effect when either I or emotionality does not covary. First, $C$ can be varied independent of I only when emotionality is allowed to covary. Furthermore, the recall data of this study are unlike those obtained in previous research manipulating C. Finally, rated emotionality accounts as well for the recall data as rated concreteness. These data lend support to the hypothesis that the effect of noun $\mathrm{C}$ can be attributed, almost entirely, to noun I.

\section{REFERENCES}

OSGOOD, C. E., SUCI, G. J., \& TANNENBAUM, P. H. The measurement of meaning. Urbana, Ill.: Univer. Illinois Press, 1957.

PAIVIO, A. Abstractness, imagery, and meaningfulness in paired-associate learning. J. verbal Learn. verbal Behav., 1965, 4, 32-38.

PAIVIO, A. Meaning, mediation, and memory. Research Bulletin No. 48, Dept. of Psychol., Univ. Western Ont., 1967.

PAIVIO, A., YUILLE, J. C., \& MADIGAN, S. Concreteness, imagery, and meaningfulness values for 925 nouns. J. exp. Psychol. Monogr. Suppl., 1968, 76, 1 (Part 2).

PAIVIO, A., YUILLE, J. C., \& SMYTHE, P. C. Stimulus and response abstractness, imagery, and meaningfulness, and reported mediators in paired-associate learning. Canad. J. Psychol., 1966, 20, 362-377.

\section{NOTE}

1. This research was completed while the author held a National Research Council of Canada Postdoctorate Fellowship. The research was supported by a grant from the Humanities and Social Science Research Fund of McGill University. 